\title{
POPABES (Pondok Pesantren Bebas Scabies) pada Santriwan dan Santriwati di Pondok Pesantren
}

\author{
Mardiana $^{1 *}$, Tegar Atmajaya ${ }^{2}$, Rendy Wardana ${ }^{3}$, Nur Gindawati $^{4}$, Avirda Dwi Anaya ${ }^{5}$, Anisa \\ Larasati ${ }^{6}$, Anindi Trikandini ${ }^{7}$, Dinda Ni'matul Khasanah ${ }^{8}$ \\ 1,2,3,4,5,6,7,8Universitas Muhammadiyah Kalimantan Timur \\ *Email : Mar348@umkt.ac.id
}

\begin{abstract}
Scabies is a skin disease that can be found in almost every boarding school and is considered a harmless disease. In Indonesia, as the country with the most Muslim population in the world, there are 14,798 boarding schools with a high prevalence of scabies. One thing that supports the spread of scabies is that PHBS in the santri schools (pesantren) is not good. Community empowerment activities at Al-Muhajirin Islamic Boarding School were carried out to improve the health status of female and female students. Community empowerment activities are carried out by providing health education (pre-test and post-test), pocket book training and making advocacy about room cleaning schedules, carrying out PHBS activities that include all female and female students in the Al-Muhajirin Loa Islamic boarding school. Based on the results of the spss analysis with the Independent T-Test, $\mathrm{P}$-value $=0.000<0.05$, which means there is a difference in knowledge between pre-test and post-test health education activities about School PHBS (Islamic Boarding School) and Scabies. In addition, the results of book training pocket can reduce the risk of scabies and improve personal hygiene in female and female students at Al-Muhajirin Islamic Boarding School. Therefore, community empowerment activities in the boarding school environment about Scabies can improve the health status of female students \& female students in the boarding school environment.
\end{abstract}

Keywords: Scabies, school PHBS, boarding school

\begin{abstract}
ABSTRAK: Penyakit scabies merupakan penyakit kulit yang dapat di temui hampir di setiap pondok pesantren dan dianggap sebagai penyakit yang tidak berbahaya. Di Indonesia, sebagai negara dengan jumlah penduduk muslim terbanyak di dunia, terdapat 14.798 pondok pesantren dengan prevalensi skabies cukup tinggi. Hal yang mendukung terjadinya penularan skabies salah satunya adalah PHBS di sekolah (pesantren) santri yang kurang baik.Kegiatan pemberdayaan masyarakat di Pondok Pesantren Al-Muhajirin dilkakukan untuk meningkatkan derajat kesehatan santriwandan santriwati. Kegiatan pemberdayaan masyarakat dilakukan dengan pemberian pendidikan kesehatan (pre test dan post test ), pelatihan buku saku dan pembuatan advokasi tentang jadwal bersih-bersih kamar, melaksanakan kegiatan PHBS yang mencakup seluruh santriwati \& santriwan yang ada di pondok pesantren Al-Muhajirin Loa janan. Berdasarkan hasil dari analisis spss dengan uji T-Test Independent didapatkan P-value $=0.000<0.05$ yang berarti ada perbedaan pengetahuan antara pre test dan post test kegiatan pendidikan kesehatan tentang PHBS Sekolah (Pondok Pesantren) dan Scabies.Selain itu, hasil dari pelatihan buku saku dapat mengurangi resiko penyakit skabies dan meningkatkan kebersihan diri pada santriwan \& santriwati di Pondok Pesantren Al-Muhajirin. Oleh karena itu kegiatan pemberdayaan masyarakat di lingkungan Pondok Pesantren tentang Scabies dapat meningkatkan derajat kesehatan santriwan \& santriwati di lingkungan Pondok Pesantren.
\end{abstract}

Kata Kunci: Scabies, PHBS sekolah, pondok pesantren 


\section{Pendahuluan}

Penyakit scabies merupakan penyakit kulit yang dapat di temui hampir di setiap pondok pesantren dan dianggap sebagai penyakit yang tidak berbahaya sehingga kurang mendapat perhatian baik dari penderita maupun orang-orang yang berada di sekitarnya (Badri, 2007; Yasin, 2009; Afraniza, 2011; Antariksa, 2012).Sampai saat ini scabies masih terabaikan sehingga menjadi masalah kesehatan yang umum di seluruh dunia (Heukelbach et al, 2006).World Health Organization (WHO) menyatakan scabies merupakan salah satu dari enam penyakit parasit epidermal kulit yang terbesar angka kejadiannya di dunia (Ryan, 2010). Prevalensi Scabies tertinggi di dunia yaitu berada di negara Benin Afrika Barat (28,33\%) (Salifou et al, 2013).

Pondok pesantren adalah sekolah Islam dengan sistem asrama dan pelajarnya disebut santri.Pelajaran yang diberikan adalah pengetahuan umum dan agama tetapi dititikberatkan pada agama Islam. Di Indonesia, sebagai negara dengan jumlah penduduk muslim terbanyak di dunia, terdapat 14.798 pondok pesantren dengan prevalensi skabies cukup tinggi. Pada tahun 2003, prevalensi skabies di 12 pondok pesantren di Kabupaten Lamongan adalah 48,8\% dan di Pesantren AnNajach Magelang pada tahun 2008 prevalensi skabies adalah 43\%. Santri yang mengidap skabies terganggu kualitas hidupnya karena keluhan gatal yang hebat serta infeksi sekunder.Keluhan tersebut menurunkan kualitas hidup dan prestasi akademik. Pada tahun 2008 sebanyak 15,5\% santri penderita skabies di Provinsi Aceh menurun nilai rapornya. Berdasarkan penelitian terdahulu menunjukkan prestasi belajar santri menjadi lebih rendah dibandingkan sebelum menderita skabies (Sudarsono, 2011).

Faktor-faktor Penyebab skabies banyak faktor yang menunjang perkembangan penyakit skabies, meliputi keadaan sosial ekonomi yang rendah, hiegenitas yang buruk, dan perkembangan demografik serta ekologi yang buruk merupakan hal-hal yang erat kaitannya dengan perkembangan penyakit ini. Faktor lain yang menyebabkan skabies adalah keterkaitan antara faktor sosio demografi dengan lingkungan. Salah satu cara mengatasi penyakit Scabies adalah dengan melakukan PBHS. PHBS ini salah satunya ada berada di lingkungan sekolah/Pondok Pesantren. PHBS di institusi pendidikan adalah upaya pemberdayaan dan peningkatan kemampuan untuk berperilaku hidup bersih dan sehat di tatanan institusi pendidikan. Upaya mewujudkan PHBS di sekolah mempunyai manfaat yang besar dalam meningkatkan status kesehatan siswa yakni terwujudnya sekolah bersih 
dan sehat, sehingga siswa, guru dan masyarakat lingkungan sekolah terlindungi dari berbagai gangguan dan ancaman penyakit. Selain itu dapat meningkatkan semangat proses mengajar yang berdampak pada prestasi belajar siswa (Kemenkes RI, 2008).

Menurut Departemen Kesehatan RI tahun 2002 ada 8 Indikator PHBS di sekolah yaitu indikator pertama mencuci tangan dengan air yang mengalir dan memakai sabun.Terdapat 6 langkah cara mencuci tangan yang meliputi (1) Tuang sabun ke telapak tangan, usap dan gosok dengan arah yang memutar, (2) Usap dan gosok punggung tangan secara bergantian. (3) Gosok sela-sela jari tangan, (4) Bersihkan ujung jari secara bergantian dengan posisi saling mengunci, (5) Gosok dan putar kedua ibu jari secara bergantian, (6) letakkan ujung jari ketelapak tanagan kemudian gosok perlahan (Kemenkes RI, 2008).

Indikator kedua mengonsumsi jajanan sehat di kantin sekolah. Indikator kantin sekolah terkait dengan mengkonsumsi jajanan sehat di kantin harus memiiki tempat khusus untuk mencuci tangan dengan air mengalir dan sabun.Guru di sekolah juga harus mengawasi aneka jajanan dan perilaku jajan siswa (Kemenkes RI, 2008).

Indikator ketiga menggunakan jamban yang bersih dan sehat.Indikator terkait jamban yang sehat adalah jamban yang tidak mencemari air.Jarak pemasangan septic tank dan sumur minimal 10 meter serta tidak dibuang ke selokan, empang, danau, sungai atau laut(Kemenkes RI, 2008).

Indikator keempatOlahraga yang teratur dan terukur.Indikator iniharus dilakukan secara maksimal untuk meningkatkan aktivitas fisik anak dan pembuatan ruang hijau di dalam lingkungan sekolah dapat memacu kreativitas anak dalam kegiatan olahraga (Kemenkes RI, 2008).

Indikator kelima memberantas jentik nyamuk.Terkait dengan dengan indikator tersebut dapat dilakukan dengan Pemberantasan Sarang Nyamuk (PSN) dilakukan minimal dengan 3M (mengubur barang bekas, menguras tempat penampungan air dan menutup tempat penampungan air.Minimal dalam seminggu, kegiatan membasmi sarang nyamuk harus dilakukan untuk memutus daur hidup nyamuk (Kemenkes RI, 2008).

Indikator keenam tidak merokok di sekolah.Hal ini berkaitan dengan sesuai UndangUndang Nomor 36 tahun 2009 ayat 115 tentang Kesehatan, bahwa ada tujuh tempat yang menjadi Kawasan Tanpa Rokok (KTR), yaitu fasilitas pelayanan kesehatan, tempat proses belajar mengajar, tempat anak bermain, tempat ibadah, angkutan umum, tempat kerja dan 
tempat umum. Sekolah menjadi salah satu kawasan KTR hendaknya menerapkan dengan bijak.Bila perlu, sanksi ditegakkan agar tidak ada siswa yang merokok di sekolah.Indikator ketujuh menimbang berat badan (bb) dan mengukur tinggi badan (tb) setiap 6 bulan sekali, indikator kedelapan membuang sampah pada tempatnya. Pada PHBS di Sekolah (Pondok Pesantren) di kaitkan dengan penyedian tempat sampah yang di dibagi dalam 3 kategori, yakni sampah organik, non norganik dan Bahan Berbahaya dan Beracun (Kemenkes RI, 2008).

Berdasarkan studi pendahuluan yang dilakukan di lingkungan Pondok Pesantren AlMuhajirin maka perlu untuk di lakukan kegiatan pemberdayaan masyarakat sebagai bentuk upaya peningkatan derajat kesehatan masyarakat. Selain itu, pemberdayaan masyarakat merupakan upaya untuk mewujudkan kesejahteraan dan membantu para penghuni Pondok Pesantren dan Para santriwan \& santriwati dalam menyelesaikan permasalahan kesehatan secara mandiri.Kegiatan pemberdayaan masyarakat dilaksanakan dengan tujuan meningkatkan derajat kesehatansantriwandan santriwati denganmelakukanPendidikan Kesehatan tentang PHBS sekolah (Pondok Pesantren) dan Scabies, melakukan pelatihan buku saku, serta advokasi yang merupakan alat alternatif dalam mengatasi masalah kebersihan dan penyakit scabies di Pondok Pesantren Al Muhajirin Loa Janan.

\section{Metode}

Kegiatan pemberdayaan masyarakat ini dilakukan di pondok pesantren Al-Muhajirin Loa Janan.Sasaran kegiatan dalam pemberdayaan masyarakat adalah santriwan \& santriwati pondok pesantren al-muhajirin loa janan yang berjumlah 63 orang.

Metode yang dilakukan pada kegiatanpemberdayaan masyarakat ini ada dua tahap yaitu persiapan dan pelaksanaan. Pertamaadalah tahap persiapan yang meliputi pengurusan surat perizinan ke instansi yang bersangkutan dengan mengumpulkan data, observasi awal, mengambil data dan memprioritaskan masalah. Kedua tahap pelaksanaan, dengan menggunakan metode Action Researchberupapelatihan POPABES (Pondok Pesantren Bebas Scabies) dengan mengadakan pendidikan kesehatan mengenai PHBS Sekolah (Pondok Pesantren) dan pelatihan penggunaan buku saku "PESAT SEMUR “ (Pesantren Sehat Santri bisa Makmur)“serta membuat advokasi pembuatan jadwal bersih- 
bersih kamar (menjemur kasur, membersihkan lantai, dan merendam baju dengan air panas sebulan sekali).

\section{Hasil dan Pembahasan}

Kegiatan awal pemberdayaan masyarakat yang telah dilakukan di pondok pesantren AlMuhajirin yaitu telah dilakukan surveibertujuan untuk studi pendahuluan kondisi lingkungan pondok pesantren sekaligus wawancara kepihak pondok pesantren, dapat mengubah kebiasaan buruk para santri, meningkatkan derajat kesehatan dan kesadaran akan pentingnya kebersihan diri serta kesehatan lingkungan pondok pesantren. Alasan memilih pondok pesantren ini karena belum pernah ada dilakukan penyuluhan dan pemberdayaan oleh petugas kesehatan. Para santri disana masih kurang kesadaran akan pentingnya menjaga kesehatan lingkungan serta kebersihan diri mereka dalam mencegah penyakit Scabies. Selanjutnya dilakukan pengumpulan data santriwan dan santriwati dengan menggunakan instrument kuesioner yang bertujuan untuk mengetahui permasalahan yang sedang dialami dan dapat membantu untuk mengatasi permasalahan di pondok pesantren. Pada kegiatan pengumpulan data jumlah santri yang terlibat adalah sebanyak 63 Siswa SMP.

Pada kegiatan kedua yang dilakukan adalah dengan cara melakukan pendidikan kesehatan tentang PHBS di sekolah (pesantren) dan Scabies di Pondok Pesantren AlMuhajirin Loa Janan sebanyak 44 santriwan dan santriwati. Berdasarkan hasil dari analisis dengan uji T-Test Independent didapatkan P-value $=0.000<0.05$ yang berarti ada perbedaan pengetahuan antara pre test (sebelum pendidikan kesehatan tentang PHBS dan Scabies) dan post test (sesudah pendidikan kesehatan PHBS dan Scabies).Jadi dapat disimpulkan bahwa pendidikan kesehatan tentang PHBS dan Scabies yang diberikan mengalami peningkatan terhadap pengetahuan santri.

Berdasarkan penelitian terdahulu yang dilakukan di Pondok Pesantren Mukhtaria Syafi'yah 1 Beji Tuban hasilnya menunjukkan bahwa sikap santri pondok pesantren tentang hidup bersih dan sehat dalam mencegah penyakit scabies sebelum diberikan pendidikan kesehatan dan setelah diberikan pendidikan kesehatan. Penelitian tersebut menjelaskan bahwa data pretest dan postes menghasilkan nilai P-value $=0,000(<0,05)$ yang berarti pendidikan kesehatan sangat efektif dalam mengubah sikap santri (Titin Sumiatin,2017)

Kegiatan ketiga di dalam pemberdayaan masyarakat adalah pengadaan dan pelatihan buku saku tentang 8 indikator PHBS Sekolah (Pondok Pesantren) untuk para 
santriwan dan santriwati agar mudah mengetahui apa saja PHBS sekolah (Pondok Pesantren). Isi buku saku selain mengenai 8 indikator PHBS Sekolah (Pondok Pesantren) terdapat juga pencegahan Scabies agarmereka dapat menerapkan apa saja pencegahan dari penyakit scabies. Di dalam buku saku terdapat jadwal kegiatan yang dapat mencegah Scabies. Setelah diberikan buku saku santriwan dan santriwati dapat melakukan kegiatan bersih bersih yang terjadwal guna menghindari penyakit Scabies

Penelitian terdahulu menyatakan pengetahuan santri tentang skabies dapat mengubah sikap dan perilaku praktik kebersihan diri sehingga dapat menurunkan angka kejadian scabies. Buku saku merupakan buku yang berukuran kecil dilengkapi dengan informasi dan materi-materi sehingga dapat dibawa kemana saja sesuai kebutuhan pemilik .Buku saku terbukti efektif dalam meningkatkan pengetahuan peserta didik. Penelitian sebelumnya menyatakan bahwa buku saku yang dikembangkan layak digunakan dan efektif mengingkatkan pengetahuan dan praktik konsumsi sayur dan buah pada peserta didik (Hayatun, 2018)

Kegiatan keempat pembuatan advokasi berupa jadwal bersih-bersih kamar yang dilakukan pada setiap hari minggu, hal ini bertujuan untuk santriwan dan santriwati menyadari masalah kesehatan yang sedang dihadapi, santriwan dan santriwati secara sadar mau ikut berpartisipasi dalam kegiatan penanggulangan masalah kesehatan.

Menurut studi terdahulu bahwa advokasi pesantren dalam mengontrol kebersihan diri dalam bentuk pembutan jadwal, juga merupakan faktor yang cukup penting dalam upaya pencegahan penyakit Scabies. Pihak pesantren yang terus melakukan control terhadap persoalan kebersihan, membuat para santri menjadi lebih dapat menjaga kebersihan diri dan lingkungannya (Nur asiyah, 2017).

Berdasarkan studi terdahulu upaya penumbuh kembangkan kesehatan termasuk personal hygiene dapat dilakukan dengan penggerakkan masyarakat. Penggerakkan masyarakat disini dapat dilakukan dengan memberdayakan ustadz dan santri melalui mini lokakarya kesehatan untuk membuat program kerja tentang personal hygiene yang mereka rasakan sendiri (Kemenkes, 2000). 


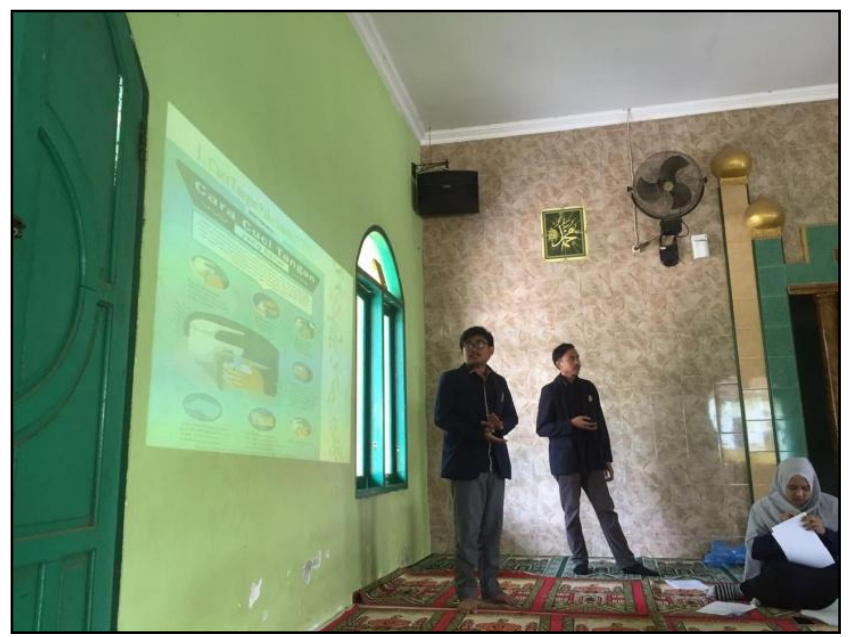

Gambar 1. Pemberian Materi tentang PHBS dan Scabies

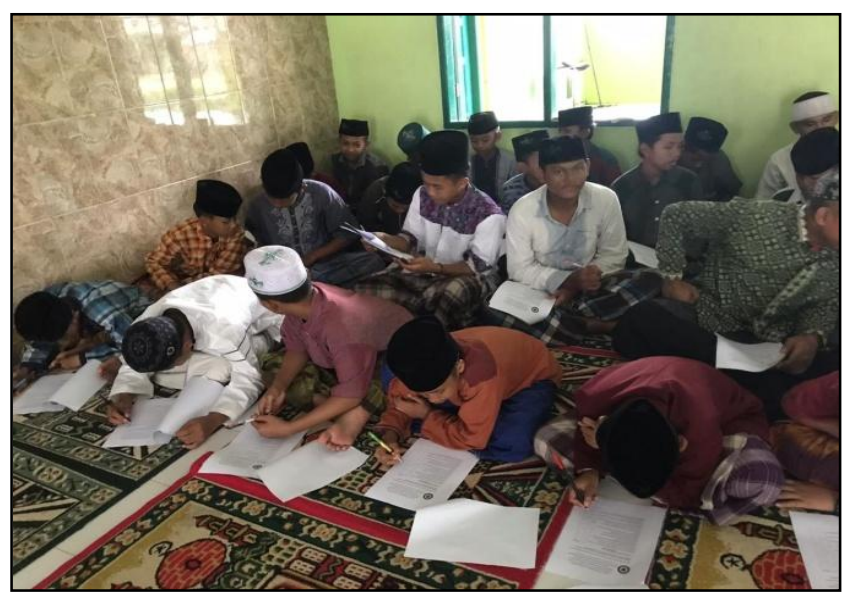

Gambar 2. Pengisian kuesioner oleh peserta Pondok Pesantren

\section{Kesimpulan}

Scabies merupakan masalah yang banyak terjadi di pondok pesantren. PHBS di sekolah (ponpes) merupakan salah satu cara alternatif untuk mengurangi scabies pada santriwan/santriwati. Kegiatan pendidikan kesehatan mengenai PHBS sekolah (pondok pesantren) mengalami peningkatan pengetahuanyang dilihat dari hasil pretest dan posttest. Kegiatan pengadaan buku saku tentang PHBS Sekolah (Pondok Pesantren) serta pencegahan Scabies secara efektif dapat mengurangi risiko terjadinya masalah scabies di pondok pesantren serta kegiatan pembuatan Advokasi telah setujui oleh pondok pesantren. Hasil dari kegiatan pemberdayaan ini adalah mewujudkan lingkungan yang sehat dan bersih, untuk mencegah dan mengurangi angka kejadian Scabies yang terjadi di Pondok Pesantren 
Al-Muhajirin.

\section{Daftar Pustaka}

Depkes RI. (2000). Buku Pedoman Pembinaan Perilaku Hidup Bersih dan Sehat di Tatanan. Jakarta. http://promkes.kemkes.go.id/phbsDiakses pada hari Selasa, 16 Desember 2019

Dewi Kusuma Mayang., Nasrul Wathoni. 2017. Artikel Review : Diagnosis Dan Regimen Pengobatan Skabies. Terdapat di: FarmakaJurnal Universitas Padjajaran Vol 15 Nomor 1.)http://jurnal.unpad.ac.id/farmaka/article/view/12898Diakses pada hari Selasa, 16 Desember 2019

Taufik Hidayat (2017, Mei) Pentingnya Perilaku Hidup Sehat dan Bersih.Diakses pada hari Kamis.http://kotaku.pu.go.id/view/3902/pentingnya-perilaku-hidup-bersih-dansehat-

Diakses pada hari Kamis, 26 Desember 2019

Jasmine Aprilia Indira., Lena Rosida., Lenie Marlinae. 2016. Hubungan Antara Pengetahuan Dan Sikap Tentang Personal Higiene Dengan Perilaku Pencegahan Penularan Sakbies Studi Observasional Pada Narapidana Anak di Lembaga Permasyarakatan Anank Kelas IIA Martapura. Jurnal Publikasi Kesehatan Masyarakat Indonesia, Vol. 3 No. 1. April 2016.https://ppjp.ulm.ac.id/journal/index.php/JPKMI/article/view/2730Diakses pada hari Selasa 16 Desember 2019

Andayani, L.S., 2007. Perilaku Santri Dalam Upaya Pencegahan Penyakit Skabies di Pondok Pesantren Ulumul Qur'an Stabat.Info Kesehatan Masyarakat. Vol. IX, No. 3, Desember 2007. http://repository.usu.ac.id/bitstream/handle/123456789/15327/ikmdes2005-\%20\%285\%29.pdf?sequence=1\&isAllowed=yDiakses hari Selasa 16 Desember 2019

Yuni Meriska (2017, Juni 6). 8 indikator PHBS, apa saja penjelasannya? PHBS.https://gizi.unisayogya.ac.id/8-indikator-phbs-apa-saja-penjelasannya-2/

di akses pada hari Rabu, 25 Desember 2019

Mading, M., \& P.B.Sopi, I. I. (2015).Kajian Aspek Epidemiologi Skabies Pada Manusia. Jurnal $\begin{array}{lllll}\text { Penyakit Bersumber } & \text { Binatang, } & \text { Vol. } & 2 & \text { No.2. }\end{array}$ http://ejournal.litbang.depkes.go.id/index.php/jpbb/article/view/8897Diakses pada hari Rabu, 25 Desember 2019

Marminingrum, P. P. (2018). Analisis faktor scabies pada santri laki-laki di pondok pesantren

Al-hasan Ponorogo.http://repository.unair.ac.id/85221/4/full\%20text.pdfDiakses pada hari Rabu, 25 Desember 2019

Ratnasari, A. F., \& Sungkar, S. (2014). Prevalensi Skabies dan Faktor-faktor yang Berhubungan di Pesantren X, Jakarta Timur.Prevalensi Skabies, Vol. 2, No. 1.http://journal.ui.ac.id/index.php/eJKI/article/viewFile/3177/3401Diakses pada hari Rabu, 25 Desember 2019 